\title{
Commentary \\ Prolactin signaling and Stat5: going their own separate ways?
} Cathrin Brisken ${ }^{1}$, Ayyakkannu Ayyanan ${ }^{1}$ and Wolfgang Doppler ${ }^{2}$

\author{
1Swiss Institute for Experimental Cancer Research, Epalinges, Switzerland \\ 2University of Innsbruck, Medical Chemistry and Biochemistry, Innsbruck, Austria
}

Correspondence: Cathrin Brisken, Swiss Institute for Experimental Cancer Research, Ch. des Boveresses 155, 1066 Epalinges, Switzerland. Tel: +41 2169258 51; fax: +412165269 33; e-mail: Cathrin.Brisken@isrec.unil.ch

Received: 14 June 2002

Revisions requested: 17 July 2002

Revisions received: 19 August 2002

Accepted: 11 September 2002

Published: 3 October 2002
Breast Cancer Res 2002, 4:209-212 (DOI 10.1186/bcr543)

(C) 2002 BioMed Central Ltd

(Print ISSN 1465-5411; Online ISSN 1465-542X)

\begin{abstract}
Miyoshi et al. compared the role of the prolactin receptor (PrIR) and its downstream mediator, the signal transducer and activator of transcription 5 (Stat5), in mammary epithelial cells in vivo by studying $\mathrm{PrIR}^{-/-}$and Stat5ab-/- mouse mammary epithelial transplants during pregnancy. At first glance, the two mutant epithelia appear to have similar defects in the differentiation of the alveolar epithelium. However, a closer examination by Miyoshi et al. revealed defects in the epithelial architecture of the smallest ducts of Stat5ab- $\mathrm{ab}^{-1-}$ transplants not apparent in the $\mathrm{PrIR}^{-1-}$ transplants, suggesting that Stat5 is more than a simple mediator of PrIR action.
\end{abstract}

Keywords: cell adhesion, mammary epithelium, prolactin receptor, Stat5, steroid hormones

\section{Introduction}

Pituitary prolactin is a key regulator of breast development [1-3]. Some prolactin is also produced by the breast epithelium itself, and local prolactin signaling can be deregulated during breast carcinogenesis [4,5]. Prolactin acts via the prolactin receptor (PrIR), a member of the cytokine receptor family [6], and its associated kinase Jak2 [7]. One of the key signaling molecules activated by the PrIR is the signal transducer and activator of transcription 5 (Stat5) $[8,9]$.

A genetic approach to address and compare the contribution of PrIR and its key signaling molecule Stat5 for mammary gland differentiation during pregnancy, by deletion of their genes, is complicated by two instances. First, two closely related Stat5 genes exist, namely Stat5a and Stat5b. They share $92 \%$ of their amino acid sequence, are partially functionally redundant, and differ mainly in their carboxy-terminal region [10]. The establishment of Stat5a and Stat5b double knockout mice is therefore mandatory. Second, because PrIR-defective mice [11] or mice carry- ing inactivated Stat5a and Stat5b (Stat5ab ${ }^{-/-}$) are infertile [12], it is not possible to study the development of their mammary glands during pregnancy. To overcome the second problem, powerful transplantation techniques have been used (for a review, see [13]). In particular, mammary epithelium from infertile mice can be engrafted to mammary fat pads of wild-type prepubertal mice that are surgically cleared of the endogenous epithelium [14].

$\mathrm{PrIR}^{-/-}$mammary epithelial cells (MECs) engrafted to cleared mammary fat pads of a wild-type host, and thus exposed to a normal endocrine milieu, undergo normal ductal development during puberty but fail to form alveoli and to differentiate into milk-secreting cells during pregnancy [15]. This indicates that the PrIR expressed in MECs is required for alveologenesis and the associated differentiation process.

Miyoshi et al. used mammary epithelial transplants of Stat5ab-/- epithelium and compared them directly with $\mathrm{PrIR}^{-/-}$epithelial transplants [16]. At first glance, the

$\mathrm{IL}=$ interleukin; MAPK = mitogen-activated protein kinase; $\mathrm{MEC}=$ mammary epithelial cell; PI3K = PI 3-kinase; PrIR = prolactin receptor; Stat5 = signal transducer and activator of transcription 5. 
expectations that the phenotypes of Stat5ab-/- and PrIR-/epithelia are similar are met. But as Miyoshi et al. looked more closely, they uncovered thought-provoking differences that tell us we still have some significant lessons to learn about the biology of these signaling molecules.

\section{Phenotypical similarities of Stat5ab-/- and PrIR $^{-/-}$epithelia}

Whole mount microscopy of mammary glands engrafted with Stat5ab-/- or $\mathrm{PrIR}^{-/-}$epithelium confirms that both mutants form a normal ductal system in the adult virgin host. At the end of pregnancy, however, when the wildtype epithelium has fully expanded and the alveoli are distended by secretion, there is no alveolar development in the PrIR-/- MEC and little development in the Stat5ab-/MEC. Expression of the milk proteins is substantially reduced in both of the mutant tissues. Together, these data confirm that Stat5 and the PrIR play an essential role in alveolar morphogenesis and differentiation.

\section{Unique defects in the differentiation of the Stat5ab-/- epithelium}

As Miyoshi et al. examined the structural organization of the epithelium at the end of pregnancy in more detail, a Stat5ab-/- epithelial-specific phenotype became apparent. The intraductal space, clearly discernable even in the smallest ducts of the $\mathrm{PrIR}^{-/-}$epithelium, is partially obliterated in the Stat5ab-/- epithelium. The epithelial cells lining in the smallest branches are of irregular shape and appear disorganized. There are multiple layers of luminal epithelial cells in the Stat5ab-/- transplants and, consequently, crowded lumina.

Electron micrography reveals that microvilli on the apical surface and tight junctions are difficult to find in Stat5ab-/epithelia, and that the intercellular spaces are disrupted. It remains most puzzling that the unique Stat5ab-/- defect becomes apparent specifically when alveolar morphogenesis is to take place. This suggests an essential and nonredundant role of Stat5 in the induction or repression of genes in the epithelial cells forming the alveoli versus those forming the ducts. A putative function of such genes is the control of intercellular adhesion in the nascent alveoli.

\section{Proliferative response to estrogen and progesterone is more profoundly inhibited in the $\mathrm{PrIR}^{-/-}$MEC compared with the Stat5ab-/- MEC}

Miyoshi et al. assessed the proliferative response of the mutant engrafted epithelia by injecting animals with estradiol and progesterone, and measuring 5'-bromo2 'deoxyuridine incorporation 48 hours later. In this assay, both mutant epithelia exhibited a reduced epithelial proliferation when compared with an engrafted wild-type cient MEC was approximately twofold higher than the inhibition of the Stat5ab-/- MEC.

Since at the end of pregnancy both mutant epithelia have perfectly completed ductal morphogenesis, and this process is under the control of estrogen and progesterone [1], it is at first sight surprising that the mutant epithelia respond differently to estradiol and progesterone in the proliferation assay. Possible explanations for the failure to detect a proliferation phenotype at the end of pregnancy are that the time of hormonal stimulation is longer or because there is compensation through many additional stimuli during pregnancy, or both. Indeed, there are other examples of transient phenotypes that disappear by the end of pregnancy (e.g. wnt-4) [17].

\section{Implications for the role of the PrIR-Jak2- Stat5 pathway in MEC differentiation}

The similarities in the defects of $\mathrm{PrIR}^{-/-}$and Stat5ab-1epithelia confirm an important contribution of the PrIR-Jak2-Stat5 pathway to estrogen/progesteroneinduced proliferation and alveologenesis. There is still much to learn regarding which genes are controlled by this pathway in the mammary epithelium.

Stat5 has anti-apoptotic activity in hematopoietic tissues [18]. Whether this also applies to the mammary epithelium remains to be established.

By searching for genes controlled by this pathway, Miyoshi et al. analyzed the expression of genes that have been previously implicated in cellular adhesion and secretory differentiation. They determined $\mathrm{Cx} 32$ as a putative target gene of the PrIR-Jak2-Stat5 pathway. Cx 32 is a connexin induced at lactation that has a potential role in the establishment of the secretory phenotype. Cx 32 expression is absent in the mutant epithelia. Whether the failure of expression is due to its direct regulation by Stat5 or to a more indirect dependence on the secretory phenotype remains to be established.

The observed subtle differences in the phenotype of $\mathrm{PrIR}^{-/-}$and Stat5ab-/- epithelia indicate that, in addition to the classical linear PrIR-Jak2-Stat5 pathway, Stat5independent pathways triggered by the activated PrIR and its associated Jak2 contribute to the proliferative response of the epithelium. Other pathways that activate Stat5 but do not involve the PrIR are also mandatory for alveologenesis (Fig. 1).

\section{PrIR-independent activation of Stat5}

The unique defect of the Stat5ab-/- mutant epithelium indicates a role of additional pathways not dependent on the PrIR for the induction of Stat5. This is supported by the reported activation of Stat5 in the mammary epithelium by epidermal growth factor [19] and by the requirement 
Figure 1

(a)

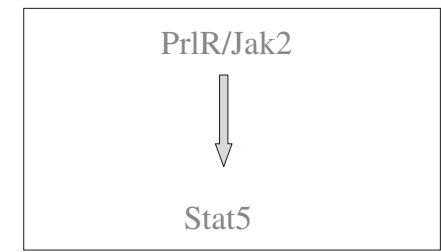

(b)

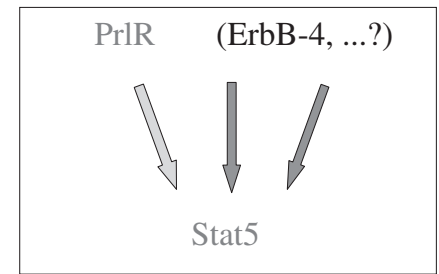

(c)

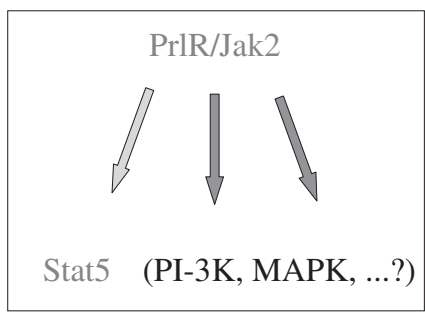

Interdependence of prolactin receptor (PrIR) and signal transducer and activator of transcription 5 (Stat5) signaling. (a) The 'classical'

PrIR-Jak2-Stat5 pathway contributes to alveolar development.

(b) Alternative routes to activate Stat5 are required for alveologenesis.

(c) Potential contribution of multiple PrIR-dependent pathways to the proliferative response to estrogen and progesterone.

$\mathrm{PI}-3 \mathrm{~K}, \mathrm{PI}$ 3-kinase; MAPK, mitogen-activated protein kinase.

for ErbB-4-triggered activation of Stat5 to trigger lobuloalveolar development during pregnancy [20].

\section{Stat5-independent pathways triggered by the activated PrIR}

As observed with other cytokine receptors with associated Jak kinases, activation of the PrIR/Jak2 by prolactin leads to the induction of other signaling pathways, such as the mitogen-activated protein kinase (MAPK) and PI 3kinase (PI3K) pathways. The relative signaling output of these different pathways appears to be crucial for the biological effect, indicating that the regulation of the balance between these pathways is of utmost importance for development and differentiation.

A recent example for a specific regulator of this balance is the suppressor of cytokine signaling SOCS-3, which has been shown to lead to the selective inhibition of Stat5 signaling but not of the MAPK pathway after IL-2 stimulation [21]. SOCS-3 might have a similar function in the mammary gland, where it is differentially regulated during development [22].
A further point to consider is that extensive crosstalk occurs between prolactin and other hormonal signaling pathways; that is, estrogen induces expression of the progesterone receptor [23] and PrIR [24], prolactin signaling induces the expression of the estrogen receptor ER $\alpha$ and ER $\beta$ in granulosa cells $[25,26]$, and prolactin has been shown to upregulate estrogen receptor expression in cultured mammary epithelial cells [27]. It is therefore important to examine the expression of the estrogen receptor and the progesterone receptor in the mutant epithelia to assess whether the number of cells, which are responsive to the hormones, is reduced in the mutant epithelia.

Finally, another possibility is that local prolactin signaling is important to the proliferative response to estrogen and progesterone. Both estrogen and progesterone act by paracrine mechanisms to induce proliferation, and it is conceivable that locally secreted prolactin is one of the mediators of these effects.

\section{Conclusion}

Stat5 was originally cloned as the 'mammary gland factor' and functionally characterized as a mediator of prolactininduced $\beta$-casein expression. The literature suggested that the basic role of Stat5 in the mammary gland was to mediate prolactin signaling, while the PrIR in turn relied heavily on Stat5 to mediate its effects.

Miyoshi et al. provide evidence that there is more than this simple mutual relationship between PrIR and Stat5. For example, inactivation of Stat5 leads to much more severe defects in the intercellular adhesion of epithelial cells than PrIR deletion, whereas PrIR deletion has a more dramatic effect on proliferation than a deletion of Stat5. Further analysis of the role of these signaling pathways will provide important insight into mammary gland morphogenesis and differentiation.

\section{Acknowledgements}

The authors thank G. Paolo Dotto for critical reading of the manuscript and Gillian Kalter for secretarial support.

\section{References}

1. Nandi S: Endocrine control of mammary-gland development in the C3H/He Crgl mouse. J Natl Cancer Inst 1958, 21:10391063.

2. Lyons WR: Hormonal synergism in mammary growth. Proc $R$ Soc Lond Ser B 1958, 149:303-325.

3. Horseman ND: Prolactin. In Endocrinology, vol 1, 4th edn. Edited by DeGroot LJ. WB Saunders; 2001:209-220.

4. Ginsburg E, Vonderhaar B: Prolactin synthesis and secretion by human breast cancer cells. Cancer Res 1995, 55:2591-2595.

5. Gill S, Peston D, Vonderhaar BK, Shousha S: Expression of prolactin receptors in normal, benign, and malignant breast tissue: an immunohistological study. J Clin Pathol 2001, 54: 956-960.

6. Goffin V, Kelly PN: The prolactin/growth hormone receptor family: structure/function relationships. J Mammary Gland Biol Neoplasia 1997, 2:7-17.

7. Rui H, Kirken RA, Farrar WL: Activation of receptor-associated tyrosine kinase JAK2 by prolactin. J Biol Chem 1994, 269: 5364-5368. 
8. Groner B, Gouilleux F: Prolactin-mediated gene activation in mammary epithelial cells. Curr Opin Genet Dev 1995, 5:587-594.

9. Ihle JN, Stravapodis D, Parganas E, Thierfelder W, Feng J, Wang $D$, Teglund S: The roles of Jaks and Stats in cytokine signaling. Cancer J Sci Am 1998, 4(suppl 1):S84-S91.

10. Liu X, Robinson GW, Gouilleux F, Groner B, Hennighausen L: Cloning and expression of Stat5 and an additional homologue (Stat5b) involved in prolactin signal transduction in mouse mammary tissue. Proc Nat/ Acad Sci USA 1995, 92:8831-8835.

11. Ormandy CJ, Camus A, Barra J, Damotte D, Lucas B, Buteau H, Edery M, Brousse N, Babinet C, Binart N, Kelly PA: Null mutation of the prolactin receptor gene produces multiple reproductive defects in the mouse. Genes Dev 1997, 11:167-178.

12. Teglund S, McKay C, Schuetz E, van Deursen JM, Stravopodis D, Wang D, Brown M, Bodner S, Grosveld G, Ihle JN: Stat5a and Stat5b proteins have essential and nonessential, or redundant, roles in cytokine responses. Cell 1998, 93:841-850.

13. Robinson GW, Hennighausen L, Johnson PF: Side-branching in the mammary gland: the progesterone-Wnt connection. Genes Dev 2000, 14:889-894.

14. DeOme KB, Faulkin LJ Jr, Bern HA, Blair PB: Development of mammary tumors from hyperplastic alveolar nodules transplanted into gland-free mammary fat pads of female $\mathrm{C} 3 \mathrm{H}$ mice. Cancer Res 1959, 19:511-520.

15. Brisken $C$, Kaur S, Chavarria T, Binart N, Sutherland R, Weinberg $\mathrm{R}$, Kelly $\mathrm{P}$, Ormandy $\mathrm{C}$ : Prolactin controls mammary gland development via direct and indirect mechanisms. Dev Biol 1999, 210:96-106.

16. Miyoshi K, Shillingford JM, Smith GH, Grimm SL, Wagner KU, Oka T, Rosen JM, Robinson GW, Hennighausen L: Signal transducer and activator of transcription (Stat) 5 controls the proliferation and differentiation of mammary alveolar epithelium. J Cell Biol 2001, 155:531-542.

17. Brisken C, Heineman A, Chavarria T, Elenbaas B, Tan J, Dey S, McMahon J, McMahon A, Weinberg R: Essential function of Wnt-4 in mammary gland development downstream of progesterone signaling. Genes Dev 2000, 14:650-654.

18. Kiesling M, Woldman I, Moriggl R, Hofmann J, Marine J-C, Ihle JN, Beug $\mathrm{H}$, Decker T: Antiapoptotic activity of Stat5 required during terminal stages of myeloid differentiation. Genes Dev 2000, 14:232-244.

19. Gallego MI, Binart N, Robinson GW, Okagaki R, Coschigano KT, Perry J, Kopchick JJ, Oka T, Kelly PA, Hennighausen L: Prolactin, growth hormone, and epidermal growth factor activate Stat5 in different compartments of mammary tissue and exert different and overlapping developmental effect. Dev Biol 2001, 229:163-175.

20. Jones FE, Welte T, Fu X-Y, Stern DF: ErbB4 signaling in the mammary gland is required for lobuloalveolar development and Stat5 activation during lactation. J Cell Biol 1999, 147:77-88.

21. Cacalano NA, Sanden D, Johnston JA: Tyrosine-phosphorylated SOCS-3 inhibits STAT activation but binds to p120 RasGAP and activates Ras. Nat Cell Biol 2001, 3:460-465

22. Tonko-Geymayer S, Goupille O, Tonko M, Soratroi C, Yoshimura A, Streuli C, Ziemiecki A, Kofler R, Doppler W: Regulation and function of the cytokine-inducible $\mathrm{SH}-2$ domain proteins, CIS and SOCS3, in mammary epithelial cells. Mol Endocrinol 2002, 16:1680-1695.

23. Haslam SZ, Shyamala G: Effect of oestradiol on progesterone receptors in normal mammary glands and its relationship with lactation. Biochem J 1979, 182:127-131.

24. Mizoguchi Y, Kim JY, Enami J, Sakai S: The regulation of the prolactin receptor gene expression in the mammary gland of early pregnant mouse. Endocr J 1997, 44:53-58.

25. Gibori G, Richards JS, Keyes PL: Synergistic effects of prolactin and estradiol in the luteotropic process in the pregnant rat: regulation of estradiol receptor by prolactin. Biol Reprod 1979, 21:419-423.

26. Telleria CM, Zhong L, Deb S, Srivastava RK, Park KS, Sugino N, Park-Sarge OK, Gibori G: Differential expression of the estrogen receptors alpha and beta in the rat corpus luteum of pregnancy: regulation by prolactin and placental lactogens. Endocrinology 1998, 139:2432-2442.

27. Edery M, Imagawa W, Larson L, Nandi S: Regulation of estrogen and progesterone receptor levels in mouse mammary epithelial cells grown in serum-free collagen gel cultures. Endocrinology 1985, 116:105-112. 